\title{
SHAPING SOCIAL LITERACY THROUGH HIV IN HIGHER EDUCATION CURRICULA
}

\section{Wood}

Faculty of Education Sciences

North-West University

Potchefstroom, South Africa

e-mail: lesley.wood@nwu.ac.za

\section{Soudien}

CEO: Human Science Research Council

Cape Town, South Africa

e-mail: csoudien@hsrc.ac.za

\section{Reddy}

Dean: Faculty of Humanities

University of Pretoria

Pretoria, South Africa

e-mail: vasu.reddy@up.ac.za

\section{ABSTRACT}

This article outlines a case for curriculum transformation in respect of HIV education, spearheaded in part by policy debates in the South African Higher Education sector, as well as by the broader social movement led by students. The authors propose that beyond statistical projections related to HIV prevalence, Higher Education institutions are duty-bound and responsible to implement knowledge projects that include curriculum reform relevant to HIV education as part of ongoing transformation initiatives. The article motivates that one approach to achieving a transformed, socially just and equitable society is through an integrated and pedagogically rigorous HIV education that will endow graduates with sound attributes to embrace the global world. In order to achieve this, the authors propose intersectionality as a conceptual model to rethink and reimagine HIV education that recognises, for example, a number of interrelated factors focusing on difference, critical diversity literacy, sexuality, masculinity and gender. The article illustrates the relevance of intersectionality to close the gap in what would otherwise be a fragmented, insular and exclusive HIV education. The authors show that an intersectional approach to HIV education will stimulate a number of beneficial effects to enhance empathy, compassion and improved human relations.

Keywords: critical diversity literacy, curriculum, HIV and AIDS, gender, intersectionality, masculinity, sexuality 


\section{INTRODUCTION}

Although the reported mean HIV prevalence for students (3.4\%) is lower than that for the general population (HEAIDS 2010a), higher education institutions still have a responsibility to ensure that students have the knowledge to make safe sexual choices, or to keep themselves healthy if they are already infected. This requires all stakeholders in the higher education sector to educate students about the biomedical facts of the virus and AIDS, about prevention measures, and also to develop a sense of compassion for those who are infected and affected (Wood 2011a). The provision of voluntary counselling and testing services, medical care and implementation of human resource practices that protect and support those infected and affected by the pandemic is recommended by policy, and, for the most part, has been well implemented in South African universities (HEAIDS 2010a). However, higher education has a responsibility, not only to protect students from infection, but also to develop graduates who can create knowledge and foster a discursive environment which is conducive to the eradication of the factors that drive the pandemic (HESA 2008, 5).

The HIV and AIDS pandemic in South Africa provides scholars of the social and cultural life of the country with an important opportunity to make sense of the dynamics that animate how the country works, how people relate to each other, and how new and innovative social pathways can be developed for imagining the country anew. It impacts on virtually every aspect of our lives in South Africa. In recent times, given the incidence of the disease and its impact on the country's mortality rates, it has come to constitute the unspoken yet innovative sub-text through which traditions of birth and death, survival and the capacity to prosper, have and are taking shape in the country. To be specific, the cultural practices that have developed in the country around funerals - mourning rituals and grieving practices, the familial and community level support structures and frameworks that have both strengthened and developed - have intimate connections to the social and human depth of the pandemic. In light of this, and in terms of rethinking what it means to be a contemporary South African, there is an urgent need to address the phenomenon of HIV and AIDs within the formal curriculum, to prepare graduates to engage, negotiate, live and work in such contexts and to play meaningful leadership roles in the processes surrounding the reconstruction of South African society. Against this, unfortunately, the point has to be made that curriculum integration at tertiary level, apart from the work of a few 'champions', has remained a rather neglected domain in HIV and AIDS research' (HEAIDS 2010a; HEAIDS 2004). It has neither fully grasped the social, political (indeed the pedagogic) significance of the pandemic nor seen the opportunities presented by the approaches South Africans have evolved to respond to it as sites of creative new social 
formation and new imaginations of a distinctly South African personhood.

In light of the comments we make above, it is true that many education bodies, specifically in Africa, have formulated policies addressing curriculum integration (van Wyk and Pieterse 2006), but integration into the formal curriculum is still the exception, rather than the rule (ACU 2001). Van Wyk and Pieterse (2006) highlight four major institutional responses to the pandemic in African institutions: promoting and advancing leadership on HIV and AIDS; prevention, care and support; mitigating the impact of HIV and AIDS; and research - with no mention of integration into the formal curriculum. Acknowledgement of this reality is important. It signals how much more engagement is necessary.

The field which has done most to integrate HIV and AIDS into the curriculum has been that of teacher education. This has been a consequence of the deliberate adoption by the Department of Education in South Africa to stimulate and develop the knowledge and capacity of teachers in this area. It saw how pivotal the position of teachers was to influence young people and how significantly schools presented themselves in educational policy as sites of prevention, care and support (Department of Basic Education 2012). However, there is ample evidence that this is not being done at enough teacher training institutions (Katahoire and Kirumira 2008), or where it is done, it is not really effectively preparing students to engage learners in meaningful learning about HIV and AIDS (Jacob, Mosman, Hite, Morisky and Nsubuga 2007; Nzioka and Ramos 2008; UNESCO IIEP 2001). Similar findings have been reported for other fields where graduates are likely to come into contact with HIV and AIDS as part of their daily work, e.g., medicine (Buskin, Lin, Houyan, Tianji and McGough 2002); dentistry (Seacat and Inglethart 2003) and nursing (Brown, Schultz, Forsberg, King, Kocik and Butler 2002; Wight, Aneshensel, Murphy and Miller-Martinez 2006).

We suggest some reasons why HIV remains largely excluded from the curriculum. Firstly, there is a general lack of understanding of the intersectionality of HIV and AIDS with social, economic, political and human rights issues (Dworkin 2005; Monteiro, Villela and Soares 2013; Wood 2011b) and so academics in other disciplines do not realize the potential of HIV for promoting transformation towards a more inclusive, contextually and culturally relevant curriculum. With intersectionality we mean a recognition of the founding work of American legal scholar, Crenshaw (1991) that emphasizes the interrelations of identity dimensions in her examination of raced and sexed identities to suggest that behaviours, identities and category formations are very closely related and help to enrich our understanding of dominance and disempowerment. Secondly, we suspect that transformation might not even be high on the agenda of most academics, who may be more immersed in discipline-related 
research than larger issues of social change. Thirdly, HIV has been conceptualized as a disease of the poor and of Black people (by the mostly White middle class) or as a punishment for promiscuous and immoral sexual behaviour (by God fearing religious factions and homophobes) and thus neither relevant nor suitable material for inclusion in the curriculum of privileged young people. And fourthly (although there are probably many more reasons, we do not have space to engage all), because the curriculum makers are uncomfortable with aspects of HIV and AIDS that fall outside of narrow disciplinary boundaries. It is easier to use the excuse of student 'AIDS fatigue' (which we suspect is often a projection of the lecturer's attitudes and feelings, rather than based on evidence that students do not want to talk about such topics), than to engage in critical self-reflection on issues of broader social justice and transformation and how they intersect with their personal beliefs and their scholarly field.

And so, in this article, we argue that HIV and AIDS is an important vehicle for transformation and diversity in the curriculum (Volks 2012) and that we lose a valuable opportunity to address issues crucial to the reduction of social injustices and promotion of sustainable development if we do not address it in the curriculum. Central therefore to the understanding, interpretation and knowledge intervention is to recognize the ways in which HIV and AIDS is profiled and represented as part of a powerful body of beliefs and assumptions concerning the supposed causes and effects (Reddy, Sandfort and Rispel 2009, xi). Schoepf (2001, 349) for example, reinforces the idea that 'disease epidemics are social processes', and maintains that 'AIDS in many cultures is weighted with extraordinary symbolic and emotional power, including ideas about social and spiritual “pollution”'. HIV and AIDS have close proximity to questions of sex, sexuality, sexual pleasure, gender, masculinity and identity formation. Almost inevitably AIDS centralizes the focus on sexual behaviours and practices that crystallizes certain fears and displaces these onto groups (notably homosexuals, women, intravenous drug users and sex workers). In effect, 'inasmuch as HIV and AIDS is a disease about the body, its varied expression as a result of culture, race, class, and sexuality stimulates and entrenches notions of difference' (Reddy 2012, 13).

All of these are deeply connected to historical anxieties that are reinforced by stereotypes, misperceptions and myths that compel us to consider interventions in the broader project of curriculum transformation in respect if HIV education. We first discuss in more detail what our understanding of HIV education is, or could be, before offering some suggestions of how it could be accommodated within the curriculum as a catalyst for much needed transformation.

\section{THE INTERSECTIONALITY OF HIV AND AIDS}


Due to the tremendous social challenges presented by the pandemic, Volks $(2012,1)$ argues that it should be regarded as an 'intellectual conundrum', rather than as a disease. A common feature of the pandemic is that it opens up both epistemological and epidemiological questions, confirming that the biological and the social conditions continually impact our changing perspectives and what we learn about the disease. The meanings that accrue as a result of the pandemic indicate that HIV and AIDS has 'changed the way we think about sex, gender, life and death, compelling us to confront topics and issues that ordinarily many of us choose to avoid' (Reddy, Sandfort and Rispel 2009, xi). Central to an understanding of the disease in an intersectional context is that the disease remains fiercely non-discriminatory in a context of persistent inequalities (and spares no colour, class, age, creed, national origin, religion, spiritual belief, and not least sexual orientation).

Universities are, at their core, knowledge sharing spaces and thus suitable environments to discuss and debate health and human rights problems (e.g., stigmatization, sexuality, gender, poverty, race, and disability) that intersect with HIV, AIDS and the experiences of the infected and affected. The inclusion of HIV and AIDS issues has tremendous potential for the general transformation of the curriculum, to enable the institution to better prepare students to live in this global, diverse and challenging world. Received and untested assumptions are also central to and remain to be investigated in integrating HIV and AIDS in the tertiary curriculum from an interdisciplinary lens. The core rationale for any syllabus change should always be to produce graduates who are well equipped to engage with and make a meaningful contribution to the world and the societies in which they live. The fundamental questions underlying an approach and consideration of the HIV and AIDS curriculum are therefore: i) what should be taught in South African institutions in the present moment; and ii) how can such a locally relevant curriculum best be achieved?

According to Volks (2012), if higher education institutions can equip students to find ways to develop new understandings of the social issues in our country, which are intricately intertwined with, for example, the causes, consequences and epistemic uses of HIV and AIDS, then positive social change will ensue. Hence, as some of the leading thinkers in society, scholars and academics should find ways to meaningfully integrate HIV and AIDS into the curriculum and research (Van Wyk and Pieterse 2006). Of course, integration does not simply mean assimilation and inclusion in an uncritical, untheoretical and instrumental manner. As academics, we need to recognize that AIDS is a universal problem and a disease that is contingent on relations and relationships, affecting everyone, not just specific demographic groups; that as concerned and engaged citizens we need to understand the pain and suffering it 
inflicts on those affected so that we can respond both personally, socially and professionally in helpful ways; and that HIV and AIDS intersects with many other pressing social issues, both as a cause and consequence. Viewed thus, it becomes clear that AIDS is an important aspect of all academic work and clearly has pedagogic effects (Volks 2012).

If one of the purposes of higher education is to develop students' ability to think critically and to continually question the status quo (Steadman and Adams 2012), then HIV and AIDS demands of academics to open up dialogue on issues such as race, class, gender, sexuality and culture, issues that may make them feel uncomfortable, but are necessary to develop student understanding of what it is to live in a diverse and socially unjust world.

The exploration and critique of such issues leads to the creation of new knowledge, the core function of a university and further education (Crewe 2012). Universities are perhaps the most important institutions in society in terms of knowledge creation, implying a moral obligation to apply this knowledge to pressing social problems (Elkana 2009) as well as recognising that new information, beyond simple transfer of factual knowledge, is one of several effects in the spectrum of uses provided by a university (Kerr 2001). For his part Fasenhest $(2010$, 484) suggests, in political economic terms, that we need to, from a perspective of research and innovation, 'come to understand universities as somewhat independent entities whose prominence derives from some fundamental shifts in our general political economy simply put, universities should be perceived as the engine that will drive the new knowledge based economy of the present day’. As Van Wyk and Pieterse $(2006,42)$ conclude in their survey of Southern African Development Community (SADC) institutions:

The university's curriculum should reflect the institution's commitment to institutionalise HIV/AIDS as a primary object of research and development, and university resources should be mobilised to facilitate the institution's unique position to respond innovatively to the disease. Several institutions in this study make barely any mention of HIV/AIDS in their curricula ...

This observation indicates that higher education in Africa is failing to educate society's leaders and future leaders to respond to the social, health, economic, developmental and political challenges that the pandemic brings. It also makes clear that students are not being developed and prepared to embrace and celebrate diverse worldviews and ontologies. The recent spate of racist and xenophobic attacks in South Africa warns us of the dangers of failing to challenge young people to rethink their assumptions and prejudices about 'others', whom they marginalise due to their skin colour, social class, sexual orientation, illness/disability, gender or nationality. As future leaders, students need to learn how to propagate inclusive thinking within their social spheres. Excluding someone for any reason is a costly exercise for society 
in psychological, physical and economic terms (Ministry of Education 2008). Although an overview of learning outcomes in higher education programmes might suggest that diversity is addressed in the curriculum, a closer reading of many of these documents makes clear that the emphasis is often more on how to 'manage diversity, but not getting to the "inclusion" level' (April and Peters 2011, 1749). Inclusion is defined as being 'about creating empowering environments of difference, where people can be themselves, comfortably contributing their full selves and all the ways in which they differ, and respect others, without making it difficult for others to be their full selves' (April and Peters 2011, 1750-1751). Inclusivity is thus a major issue for higher education to address and is increasingly more relevant in the current social movement in the higher education context where curriculum transformation features as a key component warranting change. Although the current generation of students might have grown up in post-Apartheid South Africa and ostensibly are 'post-racial', they continue, as recent events on South Africa's university campuses show, to be influenced by 'knowledge in the blood' (Jansen 2008) and the burdens of discrimination around race, sexuality, gender, geography and trauma that their parents experienced. Unless we encourage critical dialogue around such issues in higher education, the future leaders, our graduates, will not be in a position to navigate the country towards peaceful, inclusive growth and development.

On a more practical level, a HEAIDS (2010b) research report also indicated that both graduates and employers thought that students were not being adequately prepared to deal with HIV and AIDS issues in the workplace. Graduates thought that they needed to be prepared to deal with the personal, social and human dimensions of HIV and AIDS, particularly in the case of disclosure and associated stigma. The same report indicated that, even where HIV and AIDS were integrated into the curriculum, it was done in a fragmented and uncoordinated manner. Skills and capacities that students and employers identified as being important to develop during the period of study, in addition to basic facts about the nature and prevention of HIV and AIDS, included, for example:

- The development of interpersonal skills to deal with PLHIV and to be able to respond with empathy to both infected and affected persons;

- $\quad$ The ethical and legal issues of dealing with HIV positive employees/colleagues;

- $\quad$ The management of performance issues related to HIV and AIDS;

- $\quad$ Dealing with stigma;

- Handling emotions of self and others. 
All of these skills and capacities can be developed within the formal curriculum. It is equally possible to nurture a deeper knowledge of the intricate interplay of the social, political, economic, historical and cultural causes and consequences of the pandemic that allow the interrogation of the intersections of HIV and AIDS with many other issues of social injustice and exclusion. HIV and AIDS ought to be viewed holistically, making clear the intersections with other components of transformation (such as race, class, gender, sexuality, language, for example), rather than being relegated to a stand-alone, or bolted-on module (Wood 2011b). Van Wyk and Pieterse $(2006,47)$ capture the issue succinctly:

\begin{abstract}
Some higher education institutions ... have implemented generic HIV/AIDS modules as compulsory courses for all their students. This is commendable, yet for an institution to provide intellectual leadership and to produce individuals effectively engaging with the epidemic, a generic HIV/AIDS model is not sufficient. In addition to a compulsory course, a university must also provide education on HIV/AIDS which is profession-based in nature and skills-equipping in quality. Thus higher education must not only study the disease in depth within each profession and discipline, but must also equip the student with knowledge and skills to effectively engage with the epidemic. A generic HIV/AIDS module simply will not facilitate enough meaningful engagement with the disease, but could still be utilised as providing students with an introductory exposure to the epidemic and its attendant social complexities.
\end{abstract}

We would agree, but also argue that the intersectionality of HIV and AIDS makes it a perfect strategic entry point to help students to break free from the normative epistemological boundaries that constrain their thinking about issues crucial to social justice. Students in our current context need to be multi-literate to cope with the demands of a complex and everchanging world. However, just as they need to be multilingual, technologically literate and able to work in collaborative teams, they also need to learn how to live and work in a world characterized by diversity and difference in all its forms. In the next section, we discuss the concept of critical diversity literacy (CDL) (Steyn 2014) and how it may be a useful framework for thinking about how HIV and AIDS could be infused throughout the curriculum to help students to learn not only how to 'do' their chosen line of work, but also how to 'be' in this complex world.

\title{
CRITICAL DIVERSITY LITERACY
}

Recent events on university campuses throughout South Africa have made clear the depth of unhappiness, frustration and dis-ease about the pace of transformation. Occupations of buildings, marches and the challenge to university authorities and to the state, prompted by the Rhodesmustfall movement at the University of Cape Town (UCT), have put into perspective the issues that are troubling the country (see Pather 2015, 1-2). The protests were, of course, 
principally about access and the exclusionary effects that the financial management approaches of universities have had on poor students. But in the course of the protests, issues of symbolism, curriculum transformation and, critically, hetero-normativity also became flashpoints of struggle. The development of a discourse around the gendered body, initiated at UCT but also featured at other universities, is directly pertinent for the purposes of this discussion. At a symbolic level, the idea of a gendered body suggests that the body is not simply a natural object but can be seen as a metaphor to indicate the relationship of bodies to social processes, reflecting how bodies are marked across race, age, class, disease and illness, sexuality, language, and a host of other differences, which impact rethinking curricula. This indicates that the curriculum is more than just knowledge and skills, or teaching and learning, but the broad totality of experience of students, representing social practices. In this context we should likewise see the value in the assumption and request that engagements with how certain types of bodies come to be valued, privileged and entrenched is necessary to interrogate in discussions about curriculum change. In this discourse was brought to the surface the deep othering proclivities of the intersecting social systems of both whiteness and traditional cultures. Students sought to show how these issues were visibly absent, erased and ignored in what was being taught in the university and how the university was managing institutional cultures and social relations in its classrooms, residences and social spaces. Groups, that were hitherto silenced (fundamentally across linguistic, race, class and sexual orientation lines), are now claiming their right to be heard and affirmed. These events in Higher Education merely mirror and represent what is happening in society in general (or perhaps the other way around). Future leaders should be able to shed their personal notions of 'how the world should be' and develop the ability to see social interaction as multilayered, complex and dynamic. They have to be open to diverse 'truths' and, as Steyn $(2014,380)$ says, 'literate in reading the complex world of the twenty-first century'. Critical diversity literacy (CDL) enables students to carry out their personal and professional roles in a way that promotes the social good and sustainable development. As Steyn (2014) motivates, CDL requires an understanding of the dynamics of deep-rooted systems and their hegemonic discourses and practices that perpetuate the power of normative epistemologies. The intersectionality of HIV makes it a useful lens through which to confront received assumptions and explore such hegemonic thinking around class, race, culture, gender, sexuality and nationality. Although such work may have already been done within the fields of gender studies, sociology or related fields in the sciences and humanities, we argue that there is a need for it to be infused and strengthened across disciplines. Engineers and scientists also need to learn this, as much as those in the health and social sciences. 
Students who largely come from a middle-class background are generally not aware of how this privileges them, and they may struggle to see the relevance of social justice issues to their education. However, when we hear remarks such as, 'We don't want to talk about HIV, what has it to do with us?', or even more worrying, 'It is against my religion to talk about such things', it is apparent that we need to create a curriculum that challenges and disrupts such thinking. For the difficult work of reconciliation to receive renewed impetus in our country, we cannot continue to condone ignorance about how past and current inequalities continue to shape the lives of the majority. Democracy, equality and the protection of human rights may be legislated and be the subject of sophisticated policies, but that does not mean that they are operational in practice and fully enacted in our daily lives. Critical diversity literacy is thus a vital skill for students to develop. Of course, before we can transform curricula to transform the thinking of students, the curriculum makers first have to interrogate their own epistemologies and the need for change (Jansen 2008).

\section{EDUCATING THE CURRICULUM MAKERS}

As Wood (2011b) reported, most lecturers tend to have a limited understanding of HIV education and their interest in including it in their programmes depends on their personal experiences, ontologies and paradigms. Another barrier to addressing HIV-related issues is fear: of not using 'politically correct' discourse; of upsetting students or encouraging them to disclose their own experiences; and of not being able to handle their own and student emotions. These fears are perfectly understandable, given that academics are normally trained to focus on developing the intellect rather than to pay attention to emotions and feelings. However, viewing HIV through a transformation lens, within the context of a specific discipline, means that many of these fears would be unfounded. HIV and AIDS becomes an intellectual problem, rather than a personal experience.

Lecturers also complain that there is 'no room' for HIV in already full programmes, indicating that they still view it as an add-on topic, rather than a lens through which disciplinerelevant subject matter could be addressed. The potential of the curriculum to transform higher education has not been fully exploited in South Africa (Le Grange 2011) and so the possibility of HIV and AIDS as a catalyst for change needs to be researched and developed. As stated by Higher Education South Africa (HESA), an integrated response to HIV inclusion in the curriculum is needed 'within and between departments and colleges or faculties' (HESA 2008, 23). This ideal is far from reality, as most responses have been piecemeal and dependent on the interest of the specific lecturer (Wood 2011b). The next section engages how HIV education 
could be used to address concepts of masculinity and sexuality as gendered creatures of culture, as another key aspect of an inclusive and critical worldview.

\section{SEXUALITY AND MASCULINITY MATTERS}

As indicated at the beginning of this article, HIV and AIDS opens up symbolic meanings for its gendered meanings (notably sexuality and masculinity). AIDS has been constructed as a discourse emphasizing and amplifying meanings, symbols and representations that often centre on the crude categorisations of people who are affected by it: usually promiscuous homosexuals, prostitutes, haemophiliacs, women, children. There are serious consequences within the framework of HIV education for rethinking how stereoptyping reduces, essentialises, naturalises and fixes difference. HIV and AIDS compel us to challenge perceived ideas about sexual contamination. Weeks $(1985,46)$ suggests that AIDS as a metaphor 'has come to symbolize ... the identity between contagion and a kind of desire', usually in heteronormative terms. The complexities about HIV and the underlying borders and connections between sexuality and disease offer opportunities for boundaries to be made less permeable and redrawn and to challenge essentialised understandings. So in the 'fear and loathing that AIDS evokes, Weeks maintained there is a resulting conflation between two plausible, if unproven theories that there is an elective affinity between disease and certain sexual practices, and that certain sexual practices cause disease - that a third theory, that certain types of sex are disease' (Reddy 2012, 15).

In possible approaches to HIV education, the symbolic frame through which HIV and AIDS is understood offers another pedagogical entry point to discuss the meanings, practices, perceptions and stereotypes of sex and sexuality. At another level this will enable an engagement about the constructed nature of sex and gender and offer opportunities for us to consider difference and diversity, by discussing experiences of naming, labelling and oppression to offer new perspectives, contest views and to further renew the possibility to undo received notions and assumptions. A comparative rationale is evident here. These diseases do not only mark the body on the outside, but eventually dissolve and destroy the body from within. In other words, AIDS eventually wages a war on the body: the virus overpowers the body and consequently breaks it down, resulting in disintegration and disappearance. Similarly, to misrepresent, demonize, make abject bodies that do no matter (for example, homosexuals) is to ultimately intensify prejudice, oppression and ultimately misrecognise and delegitimate sexual minorities simply because of their identity. In closing this gap in our approach to curriculum change in HIV education, we anticipate, describe, and mark difference in HIV education as a 
facilitative factor rather than as something conflictual to be ignored and erased.

Underpinning all of this is the gendered dimension of sexuality which helps to open up further interrogations about the power relations between the sexes and masculinities - issues that have profound relevance in HIV education. Feminism has also questioned the naturalness of gender roles, including also heterosexuality. The construction of heterosexuality through the binary oppositions of gender help to produce hierarchies which systematically organise the oppression of women (described as compulsory heterosexuality), reinforced by patriarchal systems of power. Men sexualise the hierarchy; patriarchy is one important system (with some of the effects being rape, pornography, sexual harassment, sexual abuse of children, prostitution and pornography, and homophobia). These practices express and actualise the distinctive power of men over women. A feminist conception of sexuality in relation to these examples locates sexuality within a theory of gender inequality, meaning the social hierarchy of men over women. This approach identifies not just sexuality itself to be the dynamic of the inequality of the sexes. It is also argued that sexual difference is a function of sexual domination.

Masculinities represent the socialisation and social construction of boys into men, and reflects the unequal distribution of power between the sexes. HIV education and interventions utilising innovative and fresh approaches to consider how we undo gender arrangements that further stratify relations between the sexes are important (see for example, Akintola 2006). For instance, research on masculinities and HIV that address blurring the boundaries in the sexual and gendered division of labour, and especially in the political and social economy of care arrangements (see for example, Shefer 2007; Morrell and Jewkes 2014) and developments in the arena of Fatherhood Studies (Richter and Morrell 2006; Swartz and Bhana 2009) offer fresh perspectives to counter biomedical models and rather show the value of reshaping gendered relations (and masculinities particularly) in positive terms.

Broadly understood, any engagement with an inclusive HIV education curriculum cannot compromise nor foreclose a discussion of sexuality and masculinity as an intersectional issue because 'discourses of sexuality are in fact spaces of agency that demonstrate "conflicts of interest”' (Reddy 2012, 40). An intersectional approach, as we have argued, will disallow us from privileging singular, hierarchical and socially formed categories, behaviours and identities as the only modality of knowledge. We believe that the dialogic moments stimulated by the learning project of an inclusive HIV curriculum, should enable us to problematize and hopefully debunk myths and stereotypes that would otherwise go unquestioned.

\section{CONCLUSION}


In recent years, there has been a growing recognition of the role that universities should play in promoting transformation and inclusivity. As emphasized throughout our argument, universities are in a strategic and influential position to shape graduate thinking and to create and disseminate knowledge to advance transformation. Since HIV and AIDS is such a momentous social, economic, political and public health problem in South Africa, it stands to reason that the curriculum should create space for the intersectionality of HIV and AIDS to feature as a point of critical discussion and learning. Yet, although there is ample research on the various theoretical approaches to HIV and AIDS education and paradigms that should frame it, empirical studies that show how HIV and AIDS can be used to promote a transformative and inclusive curriculum appear to be minimal. We thus conclude that this is an area that the contemporary South African university cannot continue to overlook and ignore. Although the epidemiology of HIV and AIDS has changed over almost four decades since the virus's appearance, the epistemic challenges remain. Despite the increase in information and knowledge, we have not seen a proportional match in so far as behaviour modification and attitudinal change. The epistemic and pedagogic relevance remain therefore a necessary priority. An inclusive HIV education curriculum that gives impetus to an intersectional approach ought to assist in some ways to challenging denial and blame, resisting stigma and ignorance, and recognizing diversity and difference as an important value proposition in a transformed society. The role therefore of Higher Education, and ours in particular, has to be to facilitate debate, research and curriculum interventions across the sector to ensure our graduates are able to contribute to making the world a more equal, just, safe and inclusive place.

\section{REFERENCES}

ACU. 2001. HIV/AIDS: Towards a strategy for Commonwealth universities: Report of the Lusaka workshop. London: Association of Commonwealth Universities.

Akintola, O. 2006. Gender home-based care in South Africa: More trouble for the troubled. African Journal of AIDS Research 5(3): 237-247.

April, K. and K. Peters. 2011. Communal versus individual modalities of work: A South African investigation. Asia Pacific Journal of Business and Management 2(1): 5-36.

Brown, L., J. Schultz, A. Forsberg, G. King, S. G. Kocik and R. Butler. 2002. Predictors of retention among HIV/Hemophilia health care professionals. General Hospital Psychiatry 24: 48-54.

Buskin, S. E., L. Lin, Y. Houyuan, Y. Tianji and J. P. McGough. 2002. HIV/AIDS knowledge and attitudes in Chinese medical professionals and students before and after an informational lecture on HIV/AIDS. Journal of Public Health Management and Practice 8(6): 38-43.

Crenshaw, K. 1991. Mapping the margins: Intersectionality, identity politics, and violence against women of color. Stanford Law Review 43(6): 1241-1299.

Crewe, M. 2012. Bland management. In Third Degree, AIDS review, ed. C. Volk, 49-60. Pretoria: University of Pretoria.

Department of Basic Education. 2012. Strategy on HIV and AIDS and TB in education. Pretoria: 
Department of Education.

Dworkin, S. L. 2005. Who is epidemiologically fathomable in the HIV/AIDS epidemic? Gender, sexuality, and intersectionality in public health. Culture, Health \& Sexuality 7(6): 615-623.

Elkana, Y. 2009. Freedom and interdisciplinarity: The future of the university curriculum. Social Research 76(3): 933-942.

Fasenfest, D. 2010. A political economy of knowledge. Critical Sociology 36(4): 483-487.

HEAIDS. 2004. An HIV and AIDS audit: Interventions in South African Higher Education. Pretoria: HESA.

HEAIDS. 2010a. Creating space for HIV and AIDS in the curriculum: Rapid assessment of curricular responses. Pretoria: HESA.

HEAIDS. 2010b. An investigation of graduate competency for managing HIV/AIDS in the workplace. Pretoria: Higher Education South Africa.

HESA see Higher Education South Africa.

Higher Education South Africa. 2008. Policy framework on HIV and AIDS for higher education in South Africa. Pretoria: HESA.

Jacob, W. J., S. S Mosman, S. J. Hite, D. E. Morisky and Y. K. Nsubuga. 2007. Evaluating HIV/AIDS education programmes in Ugandan secondary schools. Development in Practice 17(1): 114-123.

Jansen, J. D. 2008. Knowledge in the blood: Confronting race and the apartheid past. Stanford, CA: Stanford University Press.

Katahoire, A. R. and E. K. Kirumira. 2008. The impact of HIV and AIDS on higher education institutions in Uganda International Institute for Educational Planning. UNESCO, Paris: France.

Kerr, C. 2001. The uses of the university. 5th ed. Cambridge, Massachusetts: Harvard University Press.

Le Grange, L. 2011. Challenges for curriculum in a contemporary South Africa. In Curriculum inquiry in South African higher education: Some scholarly affirmations and challenges, ed. E. Bitzer and N. Botha, 79-91. Stellenbosch: Sun Media.

Ministry of Education. 2008. Report of the Ministerial Committee on Transformation and Social Cohesion and the elimination of discrimination in public higher education institutions. Pretoria: Ministry of Education.

Monteiro, S. S., W. V. Villela and P. S. Soares. 2013. The interaction between axes of inequality in studies on discrimination, stigma and HIV/AIDS: Contributions to the recent international literature. Global Public Health 8(5): 519-533.

Morrell, R. and R. Jewkes. 2014. 'I am a male, although I am a little bit soft': Men, gender and care work in South Africa. In Care in context: Transnational gender perspectives, ed. V. Reddy, S. Meyer, T. Shefer and T. Meyiwa. Cape Town: HSRC Press.

Nzioka, C. and L. Ramos. 2008. Training teachers in an HIV and AIDS context: Experiences from Ethopia. Paris: IIEP/UNESCO.

Pather, C. 2015. \#RhodesMustFall: No room for ignorance or arrogance. South African Journal of Science 111(5/6): 1-2.

Reddy, V., T. Sandfort and L. Rispel, eds. 2009. From social silence to social science: Same-sex sexuality, HIV \& AIDS \& gender in South Africa. Cape Town: HSRC Press.

Reddy, V. 2012. [B]order[s]: AIDS Review. Pretoria: Centre for the Study of AIDS.

Richter, L and R. Morrell, eds. 2006. Baba: Men and fatherhood in South Africa. Cape Town: HSRC Press.

Schoepf, B. G. 2001. International AIDS research in anthropology: Taking a critical perspective on the crisis. Annual Review of Anthropology 30: 335-361.

Seacat, J. P. and M. R. Inglethart. 2003. Education about treating patients with HIV infections/AIDS: The student prospective. Journal of Dental Education 67: 630-640 
Shefer, T., K. Ratele, A. Strebel, N. Shabalala and R. 2007. From boys to men: Masculinity and risk. Cape Town: University of Cape Town Press.

Steadman, N. L. R. and L. B. Adams. 2012. Identifying faculty’s knowledge of critical thinking concepts and perceptions of critical thinking instruction in Higher Education. NACTA Journal 56(2): 9-14.

Steyn, M. 2014.Critical diversity literacy: Essentials for the twenty-first century. In Routledge international handbook of diversity studies, ed. S. Vertovec, 379-388. London: Taylor \& Francis.

Swartz, S. and A. Bhana. 2009. Teenage tata: Experience of young fathers in impoverished communities in South Africa. Cape Town: HSRC Press.

UNESCO IIEP. 2001. The impact of HIV/AIDS on the organization of education systems. Paper presented at the IIEP Virtual Institute Discussion Forum, Paris, 15 October to 9 November.

Van Wyk, B. and J. Pieterse. 2006. Institutional responses to HIV/AIDS from institutions of Higher Education in the Southern African development community. Southern African Regional Universities Association (SARUA) Centre for the Study of AIDS. University of Pretoria, South Africa. http://www.sarua.org/files/publications/SARUA_HEI_HIV_AIDS_Study.pdf (accessed 9 April 2016).

Volks, C. 2012. Third degree: AIDS review. Pretoria: Centre for the Study of AIDS.

Weeks, J. 1985. Sexuality and its discontents: Meanings, myths and modern sexualities. London: Routledge and Kegan.

Wight, R. G., C. S. Aneshensel, D. A. Murphy and K. P. Miller-Martinez. 2006. Perceived HIV stigma in AIDS caregiving dyads. Social Science \& Medicine 62: 444-456.

Wood, L. 2011a. HIV and AIDS education in pre-service teacher programmes: Lessons learned from experience in a Post-Graduate Certificate in Education. Acta Academica 43(4): 181-202.

Wood, L. 2011b. Faculty views of HIV and AIDS education in the curriculum at tertiary level. South African Journal of Higher Education 25(4): 819-837. 